\title{
Capítulo 1 - Ativismo institucional e enquadramentos interpretativos: discutindo as causas do ativismo de burocratas na criação do programa de aquisição de alimentos
}

\author{
Lucas Alves Amaral
}

\section{SciELO Books / SciELO Livros / SciELO Libros}

AMARAL, L. A. Ativismo institucional e enquadramentos interpretativos: discutindo as causas do ativismo de burocratas na criação do programa de aquisição de alimentos. In: ABERS, R. N., ed. Ativismo institucional: criatividade e luta na burocracia brasileira [online]. Brasília: Editora UnB, 2021, pp. 55-88. ISBN: 978-65-5846-159-3.

https://doi.org/10.7476/9786558461593.0002.

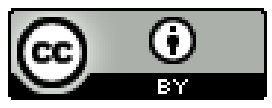

All the contents of this work, except where otherwise noted, is licensed under a $\underline{\text { Creative }}$ Commons Attribution 4.0 International license.

Todo o conteúdo deste trabalho, exceto quando houver ressalva, é publicado sob a licença Creative Commons Atribição 4.0.

Todo el contenido de esta obra, excepto donde se indique lo contrario, está bajo licencia de la licencia Creative Commons Reconocimento 4.0. 


\section{Capítulo 1}

\section{Ativismo institucional e enquadramentos interpretativos: discutindo as causas do ativismo de burocratas na criação do programa de aquisição de alimentos}

Lucas Alves Amaral

O objetivo deste capítulo é descrever e analisar a relação entre práticas de ativismo institucional no âmbito do Programa de Aquisição de Alimentos (PAA) e as ideias que mobilizam tais práticas, o que Abers, na introdução deste livro, chama de causas contenciosas. Para a autora, causas são objetivos que são defendidos contra algo (opositores, uma ordem institucional, um contexto político, etc.), seja para provocar mudanças, seja para garantir a manutenção de ordens institucionais. O meu argumento central neste texto é de que determinadas causas que orientam a ação contestatória do ativismo 
institucional devem ser vistas por meio do conceito de enquadramentos interpretativos, conceito que pode ser compreendido introdutoriamente como: "conjuntos de significados e crenças orientados à ação" (BENFORD; SNOW, 2000, p. 614, tradução nossa). ${ }^{1}$ De antemão, esse conceito nos ajuda a entender o como atores realizam agências situadas orientados por ideias e percepções da realidade institucional em que estão inseridos.

Nas ciências sociais, o conceito de enquadramentos interpretativos, oriundo do interacionismo simbólico de Erving Goffman (1974, 2012), ganhou destaque nos estudos de movimentos sociais, principalmente com Benford e Snow (2000), como forma de elucidar de que maneira ações coletivas constroem sistemas organizados de princípios para orientar sua ação (na gestão da linguagem, na comunicação de suas lutas políticas, na orientação estratégica de repertórios de ação, etc.) (OLIVEIRA, 2015). Deslocar o olhar para como ativismos que não ocorrem no âmbito de movimentos sociais, mas no interior de instituições do Estado, orientam-se por enquadramentos interpretativos nos parece uma estratégia coerente com a operacionalidade do conceito de ativismo institucional, já que este subverte a classificação da literatura sobre institucionalização e contestação.

Classicamente, a contestação era uma prática prevista para movimentos sociais, havendo uma separação dos espaços dos movimentos sociais e dos espaços dos atores da política institucional, entre eles, os burocratas (RECH; SILVA, 2016). Acoplar o “ativismo”, que é uma prática de agentes na defesa de causas, ao "institucional”, que é uma localização e um posicionamento dos agentes nas instituições políticas é, portanto, um grande ganho analítico na discussão sobre a complexidade das dinâmicas entre Estado e sociedade civil. O mesmo, a meu ver, pode ocorrer com a operacionalização do conceito de enquadramentos interpretativos na análise do ativismo institucional de burocratas, o que busco realizar aqui. ${ }^{2}$

O estudo de caso sobre a criação do PAA me levou a procurar quais as causas defendidas pelos burocratas que exerceram ativismo institucional na criação do programa, de onde se originaram essas causas e como tais causas

1 “[...] action-oriented sets of beliefs and meanings.” (BENFORD; SNOW, 2000, p. 614).

2 Esta proposta foi mais densamente desenvolvida em minha tese de doutorado (AMARAL, 2018). 
funcionavam como orientadoras de uma ação fundamental, criar o programa. $\mathrm{O}$ conceito de enquadramentos interpretativos me ajudou a sistematizar as ideias que funcionavam como causas que estes atores pareciam defender: o que chamo de enquadramentos do fortalecimento da agricultura familiar (FAF) e do fortalecimento da segurança alimentar (FSAN), como será visto a seguir.

Para descrever esses enquadramentos e as práticas de ativismo ancoradas neles na criação do PAA, exponho e analiso neste capítulo informações coletadas do estudo de caso sobre o ativismo institucional praticado no arranjo político-institucional ${ }^{3}$ do Programa de Aquisição de Alimentos. Foco em seu processo de criação, momento em que o contexto político favoreceu a ocupação de cargos na burocracia federal por atores diversos, técnicos oriundos de organizações da sociedade civil, partidários do Partido dos Trabalhadores (PT) ou de partidos coligados ao PT e, no caso do PAA, principalmente, acadêmicos e gestores públicos atuantes outrora em políticas locais relacionadas com o programa. Na análise empreendida foram utilizadas 21 entrevistas, realizadas entre 2015 e 2016, com burocratas que atuaram no Ministério do Desenvolvimento Social (MDS), na Companhia Nacional de Abastecimento (Conab), no Ministério de Desenvolvimento Agrário (MDA) e com representantes de organizações da sociedade civil atuantes no Conselho Nacional de Segurança Alimentar e Nutricional (Consea) até 2016. ${ }^{4}$

\section{Ativismo institucional, causas e enquadramentos interpretativos}

A partir da atuação de seus partidários “dentro do Estado”, movimentos sociais agem estrategicamente dentre uma miríade de repertórios de ação na ocupação de cargos burocráticos, exercendo ativismos em prol de suas causas coletivas (SANTORO; MCGUIRE, 1997; ABERS; SERAFIM;

3 Entendo o "arranjo político-institucional” como “o conjunto de regras, mecanismos e processos que define a forma particular como se coordenam atores e interesses na implementação de uma política pública específica” (PIRES; GOMIDE, 2016, p. 8).

${ }^{4}$ O marco temporal se dá devido ao impeachment da ex-presidenta Dilma Rousseff (PT), processo que reconfigurou o arranjo político-institucional do programa e a própria política nos anos seguintes. 
TATAGIBA, 2014). Assim, na trajetória do conceito de ativismo institucional, o termo foi usado para "descrever o que pessoas fazem quando assumem cargos em burocracias governamentais com os propósitos de fazer avançar agendas políticas ou projetos propostos por movimentos sociais” (ABERS; TATAGIBA, 2015, p. 73, tradução nossa). ${ }^{5}$ No entanto, alguns autores no Brasil, em especial Abers (2015, 2018, neste livro), vêm problematizando o conceito para além do vínculo de ativistas com movimentos sociais, demonstrando que o ativismo institucional diz respeito a ações que partem de compromissos com causas coletivas. Isso quer dizer que mesmo que movimentos sociais possam ter influência na produção histórica das causas que produzem ativismo institucional, nem sempre ativistas institucionais são ou foram membros desses movimentos. Abers (2015), por exemplo, mostra que a atuação ativista de burocratas no Programa Bolsa Verde aponta para a adesão desses atores às causas ambientalistas que tangenciam o Programa e não necessariamente para sua participação prévia ou simultânea em movimentos ambientalistas.

Esses achados me levaram a perceber que o ativismo institucional de burocratas no estudo de caso sobre o PAA mobilizava causas coletivas oriundas de ideias produzidas historicamente de modo complexo e de modo interativo por múltiplos atores e fontes (acadêmicos, partidos, documentos, estudos, outras políticas públicas e, também, movimentos sociais). A princípio, tais causas pareceram dificilmente sistematizáveis, já que não estavam necessariamente atreladas ao vínculo dos sujeitos que as defendiam a movimentos sociais, embora - no caso do PAA - alguns movimentos populares tenham colaborado historicamente na produção dessas ideias que se transformaram em causas. $\mathrm{O}$ conceito de enquadramentos interpretativos, então, permitiu-me sistematizar as principais ideias orientadoras dessas causas e entender as práticas de ativismo institucional no PAA. Enxergo o ativismo institucional, portanto, como um tipo particular de ação que envolve “a perseguição de oportunidades para defender

5 “[...] to describe what people are doing when they take jobs in government bureaucracies with the purpose of advancing the political agendas or projects proposed by social movements.” (ABERS; TATAGIBA, 2015, p. 73). 
causas contenciosas” (ABERS, 2019, p. 21, tradução nossa). ${ }^{6}$ Na versão do conceito que aqui utilizo, burocratas podem realizar práticas de ativismo por meio de "compromissos individualizados” (ABERS, 2015), ${ }^{7}$ embora suas causas se refiram a ideias produzidas historicamente de modo coletivo.

Ao refletir sobre a associação entre ativismo institucional, causas e enquadramentos interpretativos busquei contribuições teóricas que problematizassem a relação entre ideias e ação institucional, as quais apresento e discuto adiante. Os conceitos a seguir são elos importantes para a proposta teórica que guia minhas análises.

Em primeiro lugar, segundo Hay (2008) e Schmidt (2008), expoentes do institucionalismo construtivista, os sujeitos inseridos em instituições devem ser considerados agentes complexos que, ao mesmo tempo, são transformados e transformam as instituições em que estão inseridos. Esses sujeitos são estratégicos nas suas ações institucionais, visando realizar objetivos complexos, contingentes e constantes. Na realização de objetivos, alguns contextos favorecem determinadas estratégias em relação a outras, por isso é importante estar atento aos contextos em que os atores estão inseridos, como no caso da criação do PAA: o primeiro mandato do ex-presidente Luís Inácio “Lula” da Silva (PT), considerado um momento de alto influxo de sujeitos oriundos da sociedade civil (de fora) para dentro do Estado (D’ARAÚJO, 2007).

Para Hay (2008) e Schmidt (2008), os atores elaboram percepções dos contextos que embora sejam sempre incompletas são frutos das ideias que os orientam normativamente sobre seus modos de agir, a partir do que entendem o que "deveria ser”, produzir “ordem” ou "transformação”. Mas como são produzidas essas ideias? Elas advêm das orientações normativas dos atores e de suas noções sobre quais estratégias de ação tomar em contextos incompletos. Dito isso, é preciso compreender, além das ideias que orientam as ações, o que é a ação institucional dos atores propriamente dita. Nesse sentido, a definição de agência de Emirbayer e Mische (1998) me parece uma contribuição relevante. Segundo os autores, a agência é

6 “[...] pursuit of opportunities to defend contentious causes.” (ABERS, 2019, p. 21).

7 A autora toma o conceito de Lichterman (1995). 
Um engajamento temporalmente construído por atores de diferentes ambientes estruturais, os quais, por meio da interação entre hábito, imaginação e julgamento, tanto reproduzem, quanto transformam tais estruturas em resposta interativa aos problemas colocados pelas situações históricas mutantes. (EMIRBAYER; MISCHE, 1998, p. 970, tradução nossa). ${ }^{8}$

Os autores apontam que a agência tem três dimensões e todas são igualmente relevantes. São elas: a dimensão deliberativa, a reprodutiva e a projetiva. Assim, a agência que promove a mudança ou a manutenção institucional não deve ser vista somente na ótica de uma mudança radical e advinda de crises, mas também na ótica de ações que promovem pequenas mudanças paulatinas e incrementais, ou da agência que se configura como inação e até mesmo como resistência estratégica à mudança. Para Emirbayer e Mische, a agência no âmbito das instituições deve ser compreendida, portanto, a partir da variável "tempo" (passado, presente e futuro), podendo ela ser classificada como: $i$ ) reprodutiva, definida por orientações do passado por meio do hábito; ii) deliberativa, por partir de julgamentos e deliberações sobre o presente em relação ao passado; ou iii) projetiva, já que parte de julgamentos e projeções para o futuro a partir de questionamentos das continuidades entre passado e presente.

Em terceiro lugar, Bevir e Rhodes (2006) complementam a noção de agência apresentada anteriormente ao produzir reflexões sobre as diferenças entre agência e autonomia. Para eles, os sentidos e os significados das ações dos atores sociais emergem das instituições em que estão inseridos. Dessa forma, a agência não necessariamente se confunde com a noção de autonomia dos atores em relação a essas instituições, nem sequer se distancia totalmente delas. Indivíduos autônomos podem ter experiências, razões e adotar crenças e ações fora de todos os contextos em que estão

8 "The temporally constructed engagement by actors of different structural environments... which, through the interplay of habit, imagination, and judgment, both reproduces and transforms those structures in interactive response to the problems posed by changing historical situations.” (EMIRBAYER; MISCHE, 1998, p. 970). 
inseridos. Por outro lado, atores podem apenas agir e dar razão a novas formas sociais em relação às instituições em que estão inseridos, fazendo isso unicamente em interação com seu posicionamento nessas instituições. Assim, os autores definem o conceito de agência como "agência situada". A partir do exposto, afirmo que é possível definir ativismo institucional como um tipo de agência situada (BEVIR; RHODES, 2006) que é influenciada pela variável tempo (EMIRBAYER; MISCHE, 1998), ou seja, pode ser projetiva, deliberativa e reprodutiva.

Por fim, agrego ao modelo teórico até aqui discutido o próprio conceito de enquadramento interpretativo, que é mais consistente do que o simples termo “ideias” discutido por Hay (2008) e Schmidt (2008), conforme citado anteriormente. A intenção de agregá-lo busca identificar quais ideias orientam esta agência situada que é o ativismo institucional. Destarte, o conceito de enquadramentos interpretativos, agora de modo mais amplo, pode ser elaborado assim: sistemas cognitivos e normativos coerentes que definem pontos de vista, mecanismos de formação de identidade, princípios de ação, prescrições metodológicas e práticas para sujeitos em contextos específicos (SUREL, 2000; MENDONÇA; SIMÕES, 2012; NUNES, 2013; OLIVEIRA, 2015). Agrega-se a essa definição o que Benford e Snow (2000) sugerem em relação às três etapas constituintes de enquadramentos interpretativos: i) o diagnóstico e a construção do problema; ii) a proposição de soluções; e iii) a organização de ações e de engajamento orientada para a resolução do problema e operação das soluções. A meu ver, a partir dessa exposição, os enquadramentos interpretativos podem ter a função de inspirar e legitimar agências situadas se os utilizamos na análise do ativismo institucional. Para identificá-los é preciso observar as três etapas propostas por Benford e Snow - em primeiro lugar, o problema e as soluções -, e analisar como se dá a última delas, que pode ser entendida como uma agência situada quando aplicada a burocratas atuando como ativistas institucionais. 


\section{Ativismo institucional em prol do fortalecimento da agricultura} familiar e do fortalecimento da segurança alimentar: a criação do PAA

Segundo Grisa e Trinches (2015), o Programa de Aquisição de Alimentos (PAA) introduziu no Brasil uma nova lógica no campo das políticas de agricultura familiar e de segurança alimentar por meio da revisão do papel das compras governamentais como instrumento de incentivo à construção de reserva de mercado para pequenos produtores brasileiros, e, simultaneamente, com foco na destinação desses alimentos para melhoria da qualidade da alimentação de público vulnerável em termos de segurança alimentar e nutricional. É possível afirmar, portanto, que o PAA é organizado por problemas e soluções de dois enquadramentos interpretativos fundamentais: o fortalecimento da agricultura familiar (FAF) e o fortalecimento da segurança alimentar e nutricional (FSAN). A criação do PAA, que, como será visto, envolve ativismo institucional de burocratas, pode ser vista como o resultado de engajamento orientado para resolução do problema e operação das soluções do FAF e do FSAN.

Se buscamos resgatar interações históricas que produziram o enquadramento do FAF encontramos que este se ancora em lutas de organizações da sociedade civil e movimentos sociais agrários desde a década de 1970, bem como em estudos acadêmicos e produção de documentos diversos e experiências de políticas locais nas décadas seguintes. O FSAN, por sua vez, tem suas raízes em movimentos sociais e, principalmente, em produções técnicas e acadêmicas sobre a fome no Brasil. Embora as interações que produziram o FSAN fossem independentes do FAF, ambos se entrecruzaram na década de 1990. Já na década de 2000, uma conjunção de fatores levou acadêmicos, políticos do Partido dos Trabalhadores, gestores públicos locais e representantes de organizações da sociedade civil a se mobilizarem em torno de debates em prol da união das soluções dadas aos problemas oriundos desses dois enquadramentos interpretativos, o que culminou na construção do Programa Fome Zero, ${ }^{9}$

9 Conti (2016, p. 73) aponta que o Projeto Fome Zero quando foi assumido como programa de governo passou a ser chamado Programa Fome Zero e, posteriormente, assumiu a 
no âmbito do Instituto Cidadania. ${ }^{10} \mathrm{~A}$ oportunidade política do contexto de disputa eleitoral que o PT viveria com a candidatura de Lula em 2002 contribuiu para formação de alianças entre diferentes atores e possibilitou a formalização do Fome Zero, de onde são retiradas as principais referências do PAA. Sujeitos diversos, principalmente acadêmicos participantes desse processo, vieram a ocupar cargos na burocracia federal do primeiro mandato presidencial do PT em 2003.

\section{O fortalecimento da agricultura familiar}

No Brasil, o fomento e estruturação da produção da agricultura familiar, bem como a atenção à promoção de boa qualidade alimentar e nutricional da população, foram temas historicamente relegados a segundo plano pelas políticas públicas. Por um lado, foram negligenciados diante da lógica econômica de modernização conservadora da agricultura nacional; por outro, foram relegados dadas as condições socioculturais e políticas da realidade brasileira, marcada por desigualdade social, altos índices de pobreza e orientação da discussão do tema da alimentação a partir do caráter assistencial e emergencial da fome. Segundo Grisa e Schneider (2015), as políticas para a agricultura até a década de 1970 foram marcadas por uma estratégia nacional-desenvolvimentista na tentativa dos governos de construir a economia nacional. Já na década de 1960, essa estratégia começou a apresentar sintomas de crise, observada nas dificuldades no abastecimento alimentar da população, além de aumento da inflação, e no

identidade de estratégia Fome Zero "por entender-se que se tratava de uma estratégia de governo distinta dos programas que a compunham”. Chamo o Fome Zero de Programa ou apenas de Fome Zero ao longo deste texto. Entendo que os enquadramentos do FAF e FSAN foram acoplados formalmente neste documento.

${ }^{10}$ INSTITUTO CIDADANIA. Projeto Fome Zero: uma proposta de política de segurança alimentar para o Brasil. São Paulo: Instituto Cidadania, 2001. 
esgotamento da capacidade de importar bens necessários à industrialização do País (que, por sua vez, demandava investimentos em exportações para criar divisas) e [...] na emergência de críticas ao padrão dependente e excludente seguido pela industrialização. (GRISA; SCHNEIDER, 2015, p. 129).

Em resposta a essa crise, o governo militar introduziu no país a estratégia de modernização tecnológica da agricultura, privilegiando os grandes produtores e relegando os pequenos à marginalidade.

O fim da ditadura militar, que se configurou na reorganização do território brasileiro e na intensificação da participação dos movimentos sociais na esfera pública, trouxe novas demandas e novos atores para a cena da agricultura brasileira. Destacam-se a mobilização da sociedade civil a favor da reforma agrária durante a Assembleia Constituinte por meio da "Campanha Nacional pela Reforma Agrária”, o Movimento dos Sem Terra (MST), o Movimento dos Atingidos por Barragens (MAB), o Movimento dos Pequenos Agricultores (MPA), o Movimento de Mulheres Trabalhadoras Rurais (MMTR), a Confederação Nacional dos Trabalhadores da Agricultura (Contag), a Comissão Pastoral da Terra (CPT) e a Federação de Órgãos para Assistência Social Educacional (Fase), o Instituto Brasileiro de Análises Sociais e Econômicas (Ibase), criado em 1971 e que participou ativamente da campanha "Ação da Cidadania contra a Fome, a Miséria e pela Vida”, liderada pelo sociólogo Herbert de Souza, o "Betinho" (DELGADO, 2010; OLIVEIRA, 2015).

Na década de 1980, a medida governamental orientadora para a agricultura nacional foi a Política de Garantia de Preços Mínimos (PGPM), que visava estabilizar os preços dos alimentos para os consumidores e garantir a renda para os agricultores por meio do uso de estoques públicos. Novas demandas por políticas que não visassem apenas créditos ou regulação dos preços começaram a surgir no cenário social. Assim, desde os anos 1980, reações e reivindicações de movimentos sociais foram frequentes e incisivas em torno de melhores condições de vida e da bandeira da reforma agrária no país. Demandavam-se políticas diferenciadas de crédito e de assistência técnica e legislação trabalhista a favor dos pequenos produtores (GRISA, 2012; GRISA; SCHNEIDER, 2015; PORTO, 2014). 
A década de 1990 foi marcada por uma política governamental menos interventora nos mercados agrícolas. A partir do governo Collor e, em seguida, nos governos Itamar Franco e Fernando Henrique Cardoso, reformas administrativas e privatizações deram o tom da intervenção do governo no país. Nesse contexto, uma série de órgãos reguladores foram extintos e o volume de crédito rural concedido à agricultura nacional foi tímido e constante. Foi nessa conjuntura que surgiu a Companhia Nacional de Abastecimento (Conab), uma das principais executoras do PAA.

Simultaneamente, alguns conflitos fundiários ocorreram com violência pelo Brasil, entre eles, os eventos que resultaram numa série de mortes no confronto entre trabalhadores Sem Terra e policiais militares. Em decorrência desses eventos, várias reivindicações e contestações da sociedade civil passaram a gerar pressão sobre o governo federal em prol de políticas de crédito, melhoria de preços e incentivos à comercialização (GRISA; SCHNEIDER, 2015); entre elas, reinvindicações anuais chamadas de "Grito da Terra”. O Grito da Terra se tornou um evento anual de mobilizações de todos os movimentos sociais agrários do país que passaram a exigir políticas específicas para a "agricultura familiar” - categoria que ganha ressonância social.

No contexto de produção de ações e ideias dos movimentos sociais, o conceito de agricultura familiar ganhou destaque em produções acadêmicas nacionais e internacionais, reunindo os atores sociais do campo em torno de suas agendas políticas. ${ }^{11}$ Com ele, o marco de abordagem sobre a pequena produção no Brasil é transformado. Antes, as produções acadêmicas em geral tendiam a enxergar os pequenos produtores (ou campesinato) como um segmento subdesenvolvido dentro do sistema de desenvolvimento econômico nacional - o que identificamos como o "problema” do enquadramento interpretativo do FAF. A categoria "agricultura familiar”, ao contrário, tende a considerar os aspectos positivos do segmento, tais como seu papel de "significativo desenvolvimento da produção de alimentos no

${ }^{11}$ Segundo Picolloto (2014, p. 67), uma pesquisa inovadora produzida em articulação com a Confederação Nacional dos Trabalhadores na Agricultura (Contag) por José Graziano da Silva e uma equipe de pesquisadores no final da década de 1970 foi muito relevante na contribuição acadêmica da importância da pequena produção no Brasil. 
Brasil e em grande parte do mundo desenvolvido” (PICOLOTTO, 2014, p. 68). A categoria faz parte da solução encontrada na organização do FAF.

Várias pesquisas acadêmicas sobre a agricultura familiar no Brasil passaram a ser nomeadas sob o rótulo de "Sociologia do Novo Rural", deslocando referências setoriais anteriores que confundiam agricultura com grande produção e monocultura. No debate acadêmico, por meio de pesquisas e produções em rede com organismos governamentais e internacionais, argumentou-se que a agricultura familiar tinha um papel importante no desenvolvimento nacional. A categoria também foi mobilizada por atores sociais, principalmente pelo sindicalismo dos trabalhadores rurais; e foi, ainda, utilizada em ações do Estado por meiode políticas públicas (PICOLOTTO, 2014), tal como o Programa de Fortalecimento da Agricultura Familiar (Pronaf). O Pronaf é uma política

destinada a fornecer créditos com baixa taxa de juros de custeio e investimento aos agricultores familiares ou suas organizações, ficando sua execução a cargo, basicamente, de bancos públicos federais, com destaque ao Banco do Brasil. (OLIVEIRA, 2015, p. 33).

Observa-se que ideias sobre a solução dos problemas da agricultura familiar vão sendo elaboradas, entre elas o fornecimento de créditos para pequenos produtores. No entanto, as soluções não param por aí.

Müller (2007) aborda experiências de compras públicas da agricultura familiar na década de 1990 desenvolvidas por prefeituras governadas pelo PT - em especial, Belo Horizonte e Porto Alegre - que ofereceram um novo modelo de solução ao problema do FAF: a garantia de mercado para agricultores familiares. Aliás, já na década de 1980 no estado de São Paulo uma experiência de compra pública da agricultura familiar com destinação a merenda escolar também foi realizada no governo Franco Montoro.

Assim, o enquadramento dado à agricultura familiar no Brasil anteriormente ao PAA vai construindo soluções, tal como a demanda dos movimentos sociais por políticas públicas predominantemente crediárias e compensatórias. A produção interativa que ocorre nas lutas sociais, nos debates acadêmicos surgidos na década de 1980 e nas políticas implementadas na década de 1990, engendra o enquadramento do FAF, acrescentando outras ideias às 
soluções como, por exemplo, a garantia de mercado, mas, principalmente, o incentivo ao associativismo e à valorização dos modos de vida dos agricultores familiares, conclusão advinda das entrevistas que realizei. Inclui-se ao FAF a noção de que fortalecer a agricultura passa por construir condições de autonomia e "empoderamento" para os pequenos agricultores familiares.

Dito isso, a partir dos processos interativos apresentados, é possível afirmar que o conjunto de ideias acadêmicas, o surgimento do Pronaf, as iniciativas de movimentos sociais e organizações da sociedade civil, bem como as iniciativas de compras públicas da agricultura familiar na década de 1990 contribuíram para a construção dos princípios organizadores de ação que sustentam o enquadramento interpretativo do FAF. Após esforço de sistematização, defendo que as ideias-chave (ou seja, as soluções apresentadas ao problema da agricultura familiar no Brasil) deste enquadramento são: i) foco na "produção" de alimentos como resposta à vulnerabilidade e à marginalização histórica dos agricultores familiares; ii) o incentivo aos “modos de vida comunitária”, ou seja, a organização dos agricultores familiares por meio de associações e cooperativas, bem como a sua "participação política”; iii) as garantias de crédito e de mercado como soluções prioritárias para os problemas da agricultura familiar no Brasil. Para colocar tais soluções em prática, ações estratégicas passam a ser fundamentais, a principal delas, a criação de políticas públicas que contribuam para a realização das ideias-chave apresentadas anteriormente. É aí que a luta por criar o PAA se encaixa como estratégia de ação orientada pelo enquadramento do FAF, principalmente pelas ideias-chave 1 e 2 expostas anteriormente.

\section{O fortalecimento da segurança alimentar e nutricional}

O enquadramento do FSAN, por sua vez, pode ter sua construção histórica situada nas décadas de 1980 e 1990, por meio de uma série de interações mediadas por contribuições acadêmicas, estudos sobre a fome no Brasil e, principalmente, pela interação entre organizações da sociedade civil por meio da "Ação da Cidadania Contra a Fome”, do Fórum Brasileiro de Segurança Alimentar e Nutricional (uma rede de organizações da sociedade civil), das universidades e de partidos políticos, em especial, o 
PT. Inicialmente, o principal problema do FSAN foi a fome no Brasil. Até a década de 1980, a temática da alimentação era debatida a partir da escassez de alimentos que grupos sociais sofriam no país. Discutia-se, portanto, se a produção nacional seria suficiente para alimentar a nação. Percebe-se, desde aí, um cruzamento entre os problemas da fome e da agricultura no país, e esta última (embora geralmente oriunda de grandes proprietários) despontava como uma resposta para a fome nacional.

Grisa (2012) aponta que a segurança alimentar e nutricional se tornou um referencial setorial de política pública no Brasil no governo Sarney por meio do documento "Segurança Alimentar: proposta de uma política contra a fome”, elaborado por uma equipe de técnicos a convite da Superintendência de Planejamento do Ministério da Agricultura. Conti (2016), por sua vez, assinala que a partir da década de 1980 organizações sociais e acadêmicos produziram uma pesquisa cujos principais resultados foram publicados na obra "Raízes da fome” (MINAYO, 1985). Em 1986 foi realizada a $1^{\text {a }}$ Conferência Nacional de Alimentação e Nutrição em conjunto com a $8^{\text {a }}$ Conferência Nacional de Saúde, com participação ativa da sociedade civil e instituições governamentais. Como resultado, foi gerado o documento "Política Nacional de Segurança Alimentar e Nutricional”. A concepção de segurança alimentar e nutricional cunhada no documento e no evento dava ênfase à autossuficiência alimentar nacional e ao acesso universal aos alimentos, além de sinalizar as diretrizes de uma política nacional de segurança alimentar e a constituição de um Conselho Nacional de Segurança Alimentar (GRISA, 2012) que, de fato, veio a existir em 1993 e, posteriormente, em 2003. ${ }^{12}$ Observa-se aqui uma ampliação das soluções dadas aos problemas da segurança alimentar no país, não apenas focada no combate genérico à fome, mas visando soluções específicas voltadas para isso, tal como a constituição de um Conselho e, posteriormente, a constituição de um sistema integrado de segurança alimentar e nutricional no país.

É importante salientar que as soluções do FSAN se ampliam com o diagnóstico, consolidado na Conferência de 1986, de que

${ }^{12}$ Em 2019 foi anunciada a extinção do Consea, após sua reativação em 2003. 
a fome e a insegurança alimentar [no Brasil] derivavam da incapacidade de acesso aos alimentos, diferentemente da compreensão [...] de que a segurança alimentar dependia estritamente da capacidade de produção agrícola e do abastecimento alimentar de um país. (GRISA, 2012, p. 189).

Dessa forma, a questão ganha um matiz político, envolvendo o tema da desigualdade social e da diversidade cultural no Brasil.

Após a derrota de Lula (PT) nas eleições de 1989, estruturou-se um movimento chamado "Governo Paralelo" que funcionou entre 1990 e 1992 com o objetivo de propor políticas públicas inovadoras. Esse movimento também foi criado como resposta ao período Collor, em que as despesas com alimentação do Governo Federal foram reduzidas em mais de 25\%. À época foi lançado o documento "Política Nacional de Segurança Alimentar”, organizado por Lula e José Graziano da Silva (CONTI, 2016). Nesse documento, o entrecruzamento com a pauta da aquisição de alimentos da agricultura familiar já se fazia presente. O documento foi apresentado ao governo Collor, que o rejeitou. No entanto, “foi parcialmente assumido pelo governo Itamar Franco - e mais tarde se tornou a base do Programa Fome Zero" (CONTI, 2016, p. 70).

Em 1992, acadêmicos e organizações da sociedade civil se reuniram numa ampla pesquisa sobre a fome no Brasil, publicada na obra Mapa da Fome: subsídios à formulação de segurança alimentar (PELIANO, 1993). Naquele ano, no movimento que demandou o impeachment do então presidente Fernando Collor - os “caras pintadas", comandados pelo "Movimento Ética na Política” - surgiram lideranças e atores que se organizaram em torno da campanha "Ação da Cidadania contra a Fome, a Miséria e pela Vida” (CONTI, 2016). Em 1993, uma rede de pessoas e organizações, sob a liderança de Betinho, lançaram essa ação coletiva para dar visibilidade à questão da fome no país. A campanha estimulou a participação popular e a articulação de diferentes setores da sociedade civil por meio da criação de comitês locais que atuavam arrecadando e doando alimentos, bem como despertando a conscientização para o problema. Após o impeachment de Collor, alguns atores que haviam se organizaram em torno do “Governo Paralelo” criaram o Instituto Cidadania, uma organização não 
governamental (ONG) próxima às redes técnicas do Partido dos Trabalhadores e de representantes da academia e de organizações da sociedade civil que tinha grande influência e coordenação de Lula.

Ainda na década de 1990, durante o governo Itamar Franco, foi colocado em operação o primeiro Conselho de Segurança Alimentar e Nutricional (Consea), que reunia sociedade civil e representantes de instituições governamentais para debater o tema da alimentação no Brasil. Nesse tempo, ocorreram os primeiros debates sobre compras públicas de alimentos da agricultura familiar como política agrícola no âmbito federal, que poderia contribuir com entidades socioassistenciais para fortalecer o combate à fome no país. Esse debate era influenciado pela experiência de gestores e representantes de ONGs sobre o tema.

Com a eleição de Fernando Henrique Cardoso (FHC), os rumos das políticas de segurança alimentar mudaram no Brasil. O novo governo lançou o programa "Comunidade Solidária” e substituiu o Consea pelo Conselho da Comunidade Solidária. O programa conferiu selo de prioridade a 16 políticas públicas em diferentes áreas: mortalidade infantil, alimentação escolar, agricultura familiar etc. Nesse período de desmobilização dos atores articulados no "Ação da Cidadania contra a Fome” e no primeiro Consea, em 1998, foi criado o Fórum Brasileiro de Segurança Alimentar e Nutricional. O Fórum mobilizou encontros nacionais defendendo propostas de FSAN no país, bem como atuou no sentido de divulgar ideias de recriação do Consea.

O Fórum cumpriu um importante papel de articulador de acadêmicos e ativistas em torno do FSAN. Nesse sentido, por meio do Fórum, começou a ser inserida no Brasil uma agenda internacional sobre o tema da segurança alimentar e nutricional que contou com a participação de representantes de organizações da sociedade civil brasileira. Cabe destaque à Cúpula Mundial de Alimentação ocorrida em 1996, em Roma, que "começou a trazer o direito à alimentação como um elemento forte e inovador”, segundo entrevistado. ${ }^{13}$

${ }^{13}$ Entrevista XVIII [17.11.2016]. Entrevistador: Lucas Alves Amaral. Skype, 2016. 1 arquivo .mp3 (112min 44s). 
Já nos anos 2000, atores advindos do universo acadêmico, das interações do Governo Paralelo e do Fórum Brasileiro de Segurança Alimentar e Nutricional reuniram-se no âmbito do Instituto Cidadania para produzir um projeto de segurança alimentar que articulasse a complexidade das experiências vividas na última década a partir do acúmulo das reflexões sobre a fome no Brasil. Em 2001, o "Projeto Fome Zero: uma proposta de Política de Segurança Alimentar para o Brasil” foi lançado.

Para finalizar, defendo que o conjunto das iniciativas em rede com atuação de diversos atores sociais e acadêmicos (Ação da Cidadania Contra a Fome, Fórum Brasileiro de Segurança Alimentar e Nutricional, Consea e Instituto Cidadania), bem como os documentos e diagnósticos das décadas de 1980 e 1990, contribuíram para construir os princípios e ideias que sustentam o referencial interpretativo do FSAN. Assim, defendo que as soluções apresentadas ao problema da segurança alimentar e nutricional no Brasil - colocado como o problema da fome até os anos 2000 - são: i) foco no fortalecimento da segurança alimentar e nutricional por meio de ações emergenciais de combate à fome a partir de uma dimensão assistencial; ii) construção de sistemas de gestão entre União, estados e municípios nas ações, em articulação com o Consea federal e Conseas estaduais. Os temas da ênfase na diversificação alimentar, da valorização da diversidade alimentar regional e do combate a outros problemas alimentares que não só a fome, tal como a obesidade, vieram a se tornar soluções posteriores, já nos anos 2000, principalmente por influência de discussões no Consea e durante a implementação do PAA. Por fim, assim como no FAF, percebo que a luta por criar o PAA se encaixa como estratégia de ação orientada pelo enquadramento do FSAN, ou seja, como "causa” do ativismo institucional na criação do Programa.

\section{A criação do PAA}

Segundo Müller (2007), os movimentos sociais, sobretudo os populares do campo, de um modo geral não visualizaram no PAA uma política interessante no momento de sua criação. As soluções da questão agrária obtidas no acesso à crédito em relação ao Pronaf eram as suas estratégias centrais de interlocução com o governo no primeiro ano do primeiro 
mandato presidencial de Lula. O PAA visava garantir mercado aos agricultores e carregava consigo a bandeira do combate à fome, temas que ainda não faziam parte das soluções gerais demandadas pelos movimentos do campo no Brasil à época da criação do programa. Em sua dissertação, Müller (2007) demonstra, portanto, que os movimentos populares do campo não tiveram papel de destaque na criação do programa, tendo se mobilizado mais na sustentação do PAA e na reivindicação pela ampliação do Programa após 2005, conclusão considerada contraintuitiva por muitos. A autora analisa a rede de burocratas que teria criado o PAA e demonstra em sua análise de redes sociais, como constatei depois, que, em sua maioria, esses sujeitos eram oriundos principalmente do universo acadêmico e da própria gestão pública, já que alguns participaram de políticas locais de compras públicas da agricultura familiar nos anos 1980 e 1990. Ou seja, segundo Müller (2007), a rede principal de burocratas que participou ativamente da criação do PAA não é oriunda de movimentos sociais, o que minha pesquisa de campo confirmou.

Ao me deparar com as conclusões da autora, perguntei-me se o PAA teria sido criado única e exclusivamente por interesse do PT, ou da influência do discurso de posse de Lula que atestava ser prioridade de seu governo o combate à fome. Aos poucos pude constatar que, embora o PT e o Instituto Cidadania (ligado ao partido) foram centrais para unir atores diversos na criação do Projeto Fome Zero, os burocratas que contribuíram ativamente na criação do PAA não eram membros do partido. Pelo contrário, segundo os entrevistados, uma minoria tinha vinculação formal com o partido, embora seja possível afirmar que a maioria possuía afinidades normativas com o programa do governo federal à época, dada sua vinculação com as ideias-chaves dos enquadramentos do FAF e do FSAN que se configuravam como causas da criação do PAA. É possível afirmar que esses sujeitos eram, à época, apoiadores do partido. Perguntei-me, então, quais seriam os atores que teriam ocupado cargos na burocracia do novo governo federal em 2003 contribuindo na criação do programa e como teria se dado sua atuação burocrática no processo de criação do PAA. Interessava-me perceber se nesse processo haveria ou não ocorrido ativismo institucional e, em caso afirmativo, como e por quê (ou seja, orientado por quais causas). Vejamos os achados derivados dessas questões. 
Em primeiro lugar, nos relatos sobre o processo de criação do PAA, o perfil de pessoas que ocupavam cargos-chave na burocracia de instituições centrais no novo governo e que foram citados como responsáveis pela criação do PAA era formado, de fato, tal como constatou Müller (2007), em sua maioria, por acadêmicos e gestores que participaram de programas locais de compras públicas da agricultura familiar nas décadas de 1980 e 1990. Além disso, alguns representantes de organizações da sociedade civil atuantes no Fórum Brasileiro de Segurança Alimentar desempenhavam funções na burocracia federal. O que era comum a todos esses sujeitos, isso sim, era o fato de todos terem atuado no processo de criação do Programa Fome Zero no âmbito do Instituto Cidadania em meados de 2000 e 2001. Assim, em segundo lugar, é possível afirmar que o Instituto Cidadania e o Programa Fome Zero foram o espaço e o programa agregadores de uma rede de atores diversos oriundos de diferentes espectros sociais. Defendo que esta agregação se dá, centralmente, pelo compartilhamento entre esses sujeitos de preocupações comuns relativas a seus vínculos aos enquadramentos do FAF e do FSAN.

Em terceiro lugar, em consonância com a última afirmação, os entrevistados de minha pesquisa que foram atuantes na criação do PAA afirmaram firmemente que os burocratas envolvidos na criação do PAA se orientaram por “preocupações genuínas” com os problemas ou da agricultura familiar no país ou da fome no Brasil, ou ambos os problemas conectados, já que tais questões foram acopladas por meio de uma solução no PAA: as compras públicas da agricultura familiar para destinação de alimentos a entidades socioassistenciais. Isso me colocava diante da noção de compromisso com causas. No entanto, parecia-me que essas causas não eram as causas defendidas pelos movimentos sociais naquele contexto. Os movimentos agrários demandavam crédito continuamente nos últimos anos da década de 1990 e início dos anos 2000, e não a garantia de mercado para agricultores familiares por meio de compras públicas.

Isso o que chamo agora de “preocupações genuínas” derivavam das trajetórias pregressas dos burocratas atuantes na criação do PAA no universo acadêmico, na gestão pública e em áreas técnicas de organizações da sociedade civil. Ou seja, é possível afirmar que tais preocupações, em geral, não se conectavam exclusivamente ou prioritariamente com os movimentos sociais 
agrários ou com a Ação da Cidadania Contra a Fome, movimento ligado ao FSAN. Essas afirmações são elucidadas no trecho de entrevista a seguir.

Eu acho que o que acontece é que as pessoas que vinham trabalhando [na criação do PAA em 2003] eram pessoas que tinham uma vinculação com movimentos muito parcial, mais pelo trabalho como técnicos. Então, por exemplo, o [nome] não era indicado de nenhum movimento, nem no MDA nem aqui, nem o [nome], nem nenhum dos secretários. Então eram técnicos, com experiência acadêmica, que trabalhavam com agricultores familiares e com movimentos sociais. Agora, não eram pessoas que vinham indicadas necessariamente dos movimentos. Era da trajetória da carreira mesmo. [...] E mesmo os burocratas que já trabalhavam lá antes, que vinha do Ministério da Agricultura, do grupo de criação do Pronaf, eram técnicos que em algum momento foram envolvendo um ativismo no trabalho, parcerias com agricultores e movimentos, mas ninguém era indicado por movimentos. Eu vejo por exemplo, [nome] foi uma pessoa que trabalhou desde o início da criação do Pronaf, na área de crédito, e ele saiu agora, nessa leva que saiu do MDA com a extinção do Ministério. O [nome] era servidor do RS também... Claro, sempre teve uma militância, mas veio cedido para cá e trabalhou a vida inteira aqui. Claro que ele tinha um compromisso com a agricultura familiar, foi criando vínculos, com os movimentos, mas ele não era bancado por nenhum movimento e o ativismo dele não foi menor por conta disso. ${ }^{14}$

Com o passar das entrevistas e análise das mesmas, constatei que os relatos sobre os eventos que antecederam a criação do PAA remontavam a um dos primeiros encontros do Consea, Conselho reativado no início do primeiro mandato de Lula, que iniciou seu governo com um discurso de posse que colocava o combate à fome entre suas prioridades. Em resumo, o

${ }^{14}$ Entrevista XI [18.08.2016]. Entrevistador: Lucas Alves Amaral. Brasília, 2016. 1 arquivo .$m p 3$ (63min 50s). 
documento “Diretrizes de Segurança Alimentar ao Plano Safra 2003/2004”, foi apresentado pelo conselheiro Plínio de Arruda Sampaio, que teria recebido apoio técnico ${ }^{15}$ de Guilherme Delgado, do Instituto de Pesquisa Econômica Aplicada (Ipea) e acadêmico especializado nas temáticas agrárias e políticas sociais. O documento objetivamente previa recursos do Plano Safra (plano orçamentário, criado em 2003, voltado às safras da produção agrícola nacional) para compras públicas da agricultura familiar que destinassem os produtos comprados ao combate à fome. Esse evento é contado como uma espécie de "mito de criação" do Programa de Aquisição de Alimentos por vários entrevistados.

Ao que parece, ainda, a fala do conselheiro teria incomodado gestores e ministros empossados no governo que representavam interesses conflitantes com a proposta. Esse incômodo já apontava para algumas resistências que o PAA enfrentaria para vir a existir formalmente. As resistências aqui já apontam para a natureza contenciosa em que o ativismo institucional mobiliza suas causas.

Na primeira reunião [...] do Consea, que foi aberta pelo Lula e com presença de Ministros, os diversos de todos os Ministérios que faziam parte do Consea, um conselheiro, Plínio de Arruda Sampaio, pediu a palavra e colocou a seguinte questão: "nós temos um desafio, porque se o Fome Zero vai possibilitar o acesso aos alimentos por parte de um contingente maior, visto que muitas pessoas se alimentam precariamente, é preciso que a gente também identifique quem vai produzir esses alimentos. Não deveriam ser os mesmos produtores que hoje já estão consolidados. Deve-se construir uma proposta voltada para a agricultura familiar, inclusive agricultores mais familiares, que eles próprios também estão vulneráveis à fome, deve-se abrir este mercado para eles”. Então ele propôs um plano de safra para a agricultura familiar, até hoje se chama assim, no qual nós temos o nascedouro do PAA, porque junto com o fortalecimento do Pronaf cria-se então a ideia de um programa de compras institucionais,

${ }^{15}$ Apoio orientado pelos enquadramentos do FAF e do FSAN que pode, inclusive, ser entendido como uma prática ativista em prol desses enquadramentos. 
justamente pensando, de saída, em abastecer instituições, organizações sociais que atendiam populações carentes, esse tipo de coisa, com produção da agricultura familiar. ${ }^{16}$

É justamente após este momento “iniciático”, relatado no trecho anterior, que os relatos sobre a criação do PAA passam a apontar para o que considero práticas de ativismo institucional de burocratas.

José Graziano da Silva - referência acadêmica em estudos sobre as temáticas da agricultura familiar, bem como da segurança alimentar no Brasil - foi um participante ativo na produção do Programa Fome Zero e assumiu o Ministério Extraordinário da Segurança Alimentar (Mesa) no início do governo Lula em 2003. Como foi visto, o pesquisador havia liderado com Lula a construção do documento "Política Nacional de Segurança Alimentar” durante o Governo Paralelo. Esse documento serviu como mecanismo de pressão aos governos Collor e Itamar Franco.

Como ministro do Mesa, Graziano da Silva solicitou o estudo de estratégias para a reversão de recursos do Programa Comunidade Solidária, coordenado por Ruth Cardoso nos governos de Fernando Henrique Cardoso, para o projeto de compras da agricultura familiar (a semente do PAA) que estava em construção. Diante do desafio de criar o Programa era necessário reestruturar o Comunidade Solidária, orientando seus recursos.

No comecinho do governo já recebeu a encomenda de pensar em um programa de compras. O Graziano, eu me lembro bem deste momento, foi bem marcante para mim, que foi quando o Graziano liga para o Valter Bianchini e fala: "nós vamos converter o recurso que era da Comunidade Solidária”, que era do FHC, que a esposa dele coordenava a área social, a Ruth Cardoso, e tinha um orçamento lá e tal e vamos converter isso em compras na agricultura familiar". A gente passou 6 meses, de janeiro a julho, discutindo como fazer isso, porque a 8.666 [Lei de Licitações] não permite selecionar. "Como vamos fazer isso por meio de licitação?” Então era esse marco legal que impedia.

${ }^{16}$ Entrevista XVIII [17.11.2016]. Entrevistador: Lucas Alves Amaral. Skype, 2016. 1 arquivo .mp3 (112min 44s). 
Então ali neste primeiro momento a gente recebeu esta encomenda. Então é esta a trajetória [...] Então, apesar das diretrizes [propostas no Consea] serem consideradas o documento inaugural, houve uma autonomia grande do ministro [José Graziano da Silva] no sentido de propor o PAA, completamente dentro das diretrizes, mas com uma abrangência e uma autonomia maior em relação à política agrícola, até porque os recursos na época eram integralmente recursos manejados pelo Mesa. ${ }^{17}$

Além da atitude proativa de Graziano da Silva em relação ao orçamento, após a proposta discutida no Consea exposta anteriormente o ministro teria solicitado a criação de um Grupo de Trabalho (GT) interministerial formado por MDA, Mesa, Conab, Ipea e Consea. A iniciativa e a produção desse GT apontam para como operou o ativismo institucional desempenhado naquele contexto: por meio da reunião de uma equipe interministerial alinhada pelas soluções-chave dos enquadramentos do FAF e do FSAN, e tendo uma ação estratégica derivada desses enquadramentos interpretativos a ser realizada a criação do PAA. Esse processo se deu em meio a uma grande preocupação com a celeridade de construção de uma oportunidade a partir das propostas de Diretrizes de Segurança Alimentar ao Plano Safra 2003/2004.

O processo em pauta não pode ser descrito como a simples constituição de mais um GT interministerial, pois esteve ancorado na junção de soluções-chave dos referenciais interpretativos inovadores no interior do Estado brasileiro até os anos 2000, o FAF e o FSAN. Essa inovação fica expressa na fala a seguir, quando o entrevistado compara um modelo “antigo” de atuação burocrática a um modelo “novo”, ensejado pelos novos burocratas. Nomeia-se esse grupo de burocratas como "a equipe de governo do Lula com seu time”.

Não era a galera que estava aqui [antes]. A galera que estava aqui resistente, no modelo anterior, modelo antigo. A gente teve que ir rompendo com isso. Quem trouxe isso

${ }^{17}$ Entrevista V. [10.11.2015]. Entrevistador: Lucas Alves Amaral. Brasília, 2015. 1 arquivo .mp3 (64min 10s). 
foi a equipe de governo do Lula com seu time, suas forças políticas que vieram para dentro do Estado. ${ }^{18}$

A atuação burocrática no GT demandou o que Emirbayer e Mische (1998) chamaram de ação reprodutiva: a própria criação do GT interministerial. Ou seja, a utilização dos dispositivos normativos e institucionais disponíveis no contexto. Além disso, essa atuação ocorreu por meio de agências projetivas, no sentido de produção de esforços para a transformação da ordem vigente por meio do estudo e da utilização do processo legislativo na criação de um novo marco institucional futuro.

Segundo Müller (2007), a equipe ligada à Secretaria Executiva do Ministério Extraordinário formulou o primeiro texto de redação do PAA com a intenção estratégica de "esperar” pela possibilidade de sua instituição no Legislativo brasileiro. Assim, observa-se que burocratas vinculados ao Mesa, por meio da liderança de Graziano da Silva, desempenharam papel central na atuação do GT de criação do PAA:

A equipe mais diretamente ligada à Secretaria Executiva do Mesa formulou um texto de redação simples, e ficou aguardando até que uma lei de assunto semelhante fosse enviada à Câmara de Deputados, para inserir os pontos sobre o PAA. Foram cerca de três meses entre a redação do texto e sua inserção em uma Lei. (MÜLLER, 2007, p. 89).

Foi necessário um amplo trabalho de estruturação de alternativas legais e viáveis para a caracterização legal de um programa de compras públicas da agricultura familiar e doação para entidades da rede de assistência social brasileira. Nas palavras de alguns dos entrevistados, foi necessário “cavar” uma "brecha” em uma lei de outro tema para a institucionalização do PAA. Os termos sugerem tanto entraves institucionais para a possibilidade de uma lei que viabilizasse o programa quanto a necessidade de envolvimento engajado dos burocratas a ponto de fazê-los romper com os

${ }^{18}$ Entrevista V. [10.11.2015]. Entrevistador: Lucas Alves Amaral. Brasília, 2015. 1 arquivo .mp3 (64min 10s). 
protocolos básicos que se esperam de sua função e insistir em agências situadas projetivas, deliberativas e estratégicas num contexto contencioso.

Para o Programa de Aquisição de Alimentos vir a existir foi necessário, portanto, criar um mecanismo legal de compras públicas que não precisasse atravessar os processos rígidos previstos na Lei de Licitações. Esse foi o maior entrave jurídico à criação da política. O principal debate sobre tal entrave atravessava os limites do escopo do próprio poder Executivo. Seria necessário recorrer ao Legislativo para a criação de uma lei. Acreditava-se, no entanto, que o Congresso Nacional não aprovaria uma regra que propusesse exceção à Lei de Licitações para compras públicas de uma minoria social como os agricultores familiares. Primeiro, a bancada ruralista poderia ver na exceção um conflito de interesses para os grandes produtores agropecuários brasileiros. Segundo, o lobby das merendas possuía forte influência junto aos deputados (MÜLLER, 2007). Além disso, discursos da oposição e da grande mídia sugeriam uma possível inabilidade do governo para a execução eficaz de políticas públicas.

Os membros do GT, no entanto, enxergaram uma "janela de oportunidade” a ser aproveitada no contexto de início do governo Lula. Alguns fatores apontavam para isso: o plano de governo estava alinhado com o FAF e o FSAN, oriundos de interações históricas complexas e fonte de apoios diversos; os ocupantes de cargos na burocracia estatal do arranjo político-institucional recém-criado haviam participado da criação do Programa Fome Zero, tendo consigo metas bem claras para a criação do PAA; a existência de um canal de mobilização e aproximação de organizações da sociedade civil do governo (o Consea) que criava mecanismos de pressão externa no Legislativo; por fim, a possibilidade de inclusão do futuro PAA no orçamento federal por meio do Plano Safra, uma oportunidade orçamentária vultuosa e concreta. Dito isso, fazia-se necessária uma estratégia - que pode ser identificada no relato a seguir, de um interlocutor de Grisa (2012) que participou desse processo -, indicada pelas agências de "correr contra o tempo", de "articulação” no Legislativo e de construção de "legitimidade” nas práticas ensejadas pelo GT.

E aí nós tivemos que correr porque o Plano Safra tem um calendário, então em um mês este Grupo de Trabalho que foi constituído - Ipea, Conab, MDA e Mesa - nós fizemos uma proposta - as Diretrizes ao Plano Safra - que já entrou 
na segunda reunião do Consea em fevereiro. Ao entrar no Consea, foi um pouco surpresa, não estava esperando que viesse uma coisa articulada, com a legitimidade, que já vinha apoiada pelas áreas técnicas destes três Ministérios. Aí eles pediram mais um mês. Na reunião seguinte em março, ele foi aprovado como diretrizes ao Presidente da República. (GRISA, 2012, p. 218).

Diante dos entraves apresentados, os burocratas do GT se muniram, também, de agências discursivas para negociar e se articular às redes de parlamentares da bancada do PT no Legislativo com o intuito de estudar e refletir alternativas para a criação de uma lei. Nas palavras de Müller (2007, p. 89) iniciou-se "uma intensa negociação entre os deputados da base, a Secretaria Executiva do Mesa, a Casa Civil e os Ministérios”. No entanto, além do impedimento legislativo de tramitação de uma lei que previsse exceções à Lei de Licitações, havia a variável “tempo" como um desafio à criação do PAA, pois existia uma ordem central do núcleo político do governo de que tais ações fossem rápidas. Como resultado desse processo, o GT durou apenas de janeiro a julho de 2003, considerando-se o tempo de sua mobilização e atuação, tendo obtido êxito ao contribuir com a criação e inserção do artigo 19 (a criação do PAA) ${ }^{19}$ na Lei no 10.696 de 2003 que "dispõe sobre a repactuação e o alongamento de dívidas oriundas de operações de crédito rural, e dá outras providências”.

Porque isso foi uma coisa que eu até não sabia, que eu aprendi com a prática, que era uma coisa que se fazia muito. Você queria passar determinada proposta que no fundo mereceria ser uma lei, mas para agilizar no Congresso Nacional você enxertava ela em outra lei e ela passava ali dentro. ${ }^{20}$

${ }^{19}$ Art. 19. Fica instituído o Programa de Aquisição de Alimentos com a finalidade de incentivar a agricultura familiar, compreendendo ações vinculadas à distribuição de produtos agropecuários para pessoas em situação de insegurança alimentar e à formação de estoques estratégicos (Regulamento).

${ }^{20}$ Entrevista XVIII [17.11.2016]. Entrevistador: Lucas Alves Amaral. Skype, 2016. 1 arquivo .mp3 (112min 44s). 
Basicamente, o objetivo da lei citada é organizar o Programa Especial de Crédito para a Reforma Agrária (Procera). Mas em seu artigo 19 se deu, "entre outras providências”, a criação do Programa de Aquisição de Alimentos. Tal artigo originou um marco legal importante para as soluções-chave do FAF e do FSAN nas políticas públicas brasileiras. Este pequeno e frágil artigo 19 é o ápice de um processo de inserção, na estrutura institucional do Estado brasileiro, de soluções dadas aos problemas fundamentais do FAF e do FSAN; é fruto de compromissos com as causas derivadas desses enquadramentos interpretativos. Assim, o vínculo maior dessas causas orientadoras de ativismo institucional não se deu somente com movimentos sociais, mas sobretudo com ideias produzidas interativamente por múltiplos atores, dentre os quais se incluem os movimentos sociais.

\section{Considerações finais}

Do ponto de vista da proposta teórica deste capítulo, pode-se concluir que a articulação entre ativismo institucional e enquadramentos interpretativos nos mostra a complexidade das causas que mobilizam o ativismo institucional de burocratas na implementação de políticas públicas, apontando para a história e a contribuição de múltiplos atores a essas causas. É justamente por isso que é possível afirmar, a partir deste estudo de caso, que o conceito de enquadramentos interpretativos é útil na identificação dos processos históricos dos quais advêm causas coletivas defendidas por burocratas que não são membros de movimentos sociais.

Nesta análise do ativismo institucional na criação do Programa de Aquisição de Alimentos nota-se explicitamente que, mesmo que movimentos sociais possam ter influência na produção histórica das causas que produzem ativismo institucional, nem sempre ativistas institucionais são ou foram membros diretos desses movimentos sociais. Atores oriundos da gestão pública, do universo acadêmico e de organizações da sociedade civil em geral podem praticar ativismo institucional quando ocupam cargos burocráticos, orientados pela identificação de problemas, produção de soluções e engajamento com práticas - processos oriundos dos enquadramentos interpretativos. Suas preocupações são coletivas e podem ser consoante às preocupações 
de movimentos populares, mas seus vínculos podem ser vistos como vínculos a enquadramentos interpretativos, que partem de problemas, soluções e orientações para a ação estratégica em contextos contenciosos.

No que tange ao estudo de caso aqui descrito, observou-se que o ativismo institucional na criação do PAA se deu por meio da estruturação de um Grupo de Trabalho interministerial criado depois de debates no Consea e a partir do fomento de José Graziano da Silva, do Mesa. Por meio do GT uma série de ações com vistas à construção de um marco legal do PAA foi empreendida. “Cavar” um "enxerto” numa lei de outro tema foi uma saída possível diante dos entraves do contexto à operacionalização prática das soluções-chave do FAF e FSAN por parte dos burocratas orientados por tais enquadramentos.

De acordo com a tipificação de ativismos institucionais empreendida por Brandão e Vilaça (2017, p. 12) pode-se classificar o ativismo dos burocratas do GT de criação do PAA como um "ativismo disruptivo de tipo estruturante”: "um esforço de engenharia baseado em objetivos estruturantes para promover grandes mudanças no desenho de políticas públicas”. A agência é “estruturante” pois os objetivos dos burocratas do GT foi promover uma mudança significativa no quadro da legislação brasileira, introduzindo uma alternativa à Lei de Licitações, bem como promover a inclusão de soluções centrais aos enquadramentos do FAF e do FSAN que ainda não encontravam eco em políticas públicas federais no Brasil. Além disso, o ativismo do GT pode ser entendido como “disruptivo” porque o esforço empregado pelos burocratas atuantes neste GT envolveu justamente criar e introduzir, por meio do PAA, um novo modelo de política pública que pode ser considerada paradigmática, por unir soluções importantes para o fortalecimento da agricultura familiar e da segurança alimentar e nutricional numa mesma política. Assim, as soluções-chave do FAF e do FSAN que não tinham espaço no âmbito do Estado passam a operar de modo especial no PAA.

Por questões de espaço, não analisei aqui dois processos interessantes no estudo realizado sobre a criação e implementação inicial do PAA. Primeiramente, identifiquei o privilegiamento do FAF em relação ao FSAN na orientação das agências burocráticas nos primeiros anos de implementação do programa. Esse processo partia do entendimento que a finalidade central do programa seria, além da reserva de mercado, contribuir com o 
associativismo dos agricultores familiares - solução que foi agenciada fortemente por burocratas situados no Mesa e na Conab, que eram as estruturas centrais de gestão e operação do PAA no seu desenho inicial. No entanto, esse processo mudou radicalmente a partir da extinção do Mesa em 2004, derivada, dentre outras razões, de uma crise no governo, e a consequente criação do Ministério do Desenvolvimento Social e Combate à Fome (MDS) e sua ascendência à coordenação do Programa. A criação do MDS envolveu a chegada de uma nova comunidade de atores burocráticos no âmbito da implementação do PAA, que, aos poucos, passou a privilegiar as soluções-chave do FSAN em detrimento das soluções-chave do FAF, mudando a lógica de implementação do PAA em relação ao seu projeto original. Assim, embora o PAA seja, a princípio, uma saída prática para os problemas e soluções tanto do FAF quanto do FSAN, o modo de operá-lo é fonte de controvérsias entre os burocratas implementadores do programa ao longo de sua trajetória.

Por fim, esta análise mostrou como os enquadramentos do FAF e do FSAN foram sendo articulados, ao longo das décadas anteriores à eleição de Lula em 2003, por uma rede sobreposta de defensores localizada em diversas instituições estatais e não estatais. Sustento a tese de que o PAA pode ser entendido como o resultado de um trabalho de acoplamento desses dois enquadramentos distintos. ${ }^{21}$ Esse acoplamento, no entanto, é instável em sua implementação. De todo modo, os burocratas que produziram ativismo institucional contribuíram não só para a criação institucional do PAA, mas para as colagens ideacionais do programa que já vinham sendo tecidas e são formalizadas no Programa Fome Zero. Os processos aqui indicados são melhor analisados em Amaral (2018) e serão objeto de futuras reflexões.

${ }^{21} \mathrm{O}$ acoplamento é um mecanismo de junção de duas ou mais ideias e guias de ação, processo que também é fortemente influenciado pela interação social em contextos específicos (GOFFMAN, 2012). O processo de acoplamento introduz uma nova "laminação" de significados nos enquadramentos anteriores, que não deixam de existir, mas passam a compor novas possibilidades provocadas pela junção. Um terceiro enquadramento misto surge dos frames anteriores. O processo de acoplamento é dinâmico e não se esgota em um evento ou não intenção de sujeitos isolados. 


\section{Referências}

ABERS, Rebecca Neaera. Bureaucratic activism: pursuing environmentalism inside the Brazilian state. Latin American Politics and Society, v. 66, n. 2, p. 22-44, may 2019.

ABERS, Rebecca Neaera. Ação criativa em ecologias complexas: a construção da autoridade prática de políticas associativas. 2018 (no prelo).

ABERS, Rebecca Neaera. Ativismo na burocracia? O médio escalão do Programa Bolsa Verde. In: CAVALCANTE, Pedro; LOTTA, Gabriela (org.). Burocracia de médio escalão: perfil, trajetória e atuação. Brasília: ENAP, 2015. p. 143-176.

ABERS, Rebecca Neaera; SERAFIM, Lizandra; TATAGIBA, Luciana. Repertórios de interação Estado-sociedade em um Estado heterogêneo: a experiência na era Lula. Dados - Revista de Ciências Sociais, Rio de Janeiro, v. 57, n. 2, p. 325-57, 2014.

ABERS, Rebecca Neaera; TATAGIBA, Luciana. Institutional Activism: Mobilizing for Women's Health from Inside the Brazilian Bureaucracy. In: ROSSI, Federico M.; von BÜLOW, Marisa (org.). Social Movement Dynamics: New Perspectives on Theory and Research from Latin America. London: Ashgate, 2015, p. 73-101.

AMARAL, Lucas Alves. Entre ativismos, enquadramentos e controvérsias: as ideias e as agências de burocratas no Programa de Aquisição de Alimentos (PAA). 2018. 212 f., il. Tese (Doutorado em Ciência Política) - Instituto de Ciência Política, Universidade de Brasília, Brasília, 2018. BENFORD, Robert; SNOW, David. A framing process and social movements: an overview and assessment. Annual Review of Sociology, n. 26, p. 611-639, 2000. 
BRANDÃO, Igor Dias Marques Ribas; VILAÇA, Luiz Henrique Doria. Ativismo burocrático na construção de Belo Monte e na inclusão socioprodutiva de catadores de materiais recicláveis. Artigo. In: ENCONTRO INTERNACIONAL DE PARTICIPAÇÃO, DEMOCRACIA E POLÍTICAS PÚBLICAS, 3., 30 mai. a 2 jun., Universidade Federal do Espírito Santo, Vitória, 2017.

BRASIL. Presidência da República. Conselho Nacional de Segurança Alimentar e Nutricional. Diretrizes de segurança alimentar e do desenvolvimento agrário para o Plano Safra 2003-2004 (Subsídios técnicos do CONSEA). Brasília, 2003.

BRASIL. Presidência da República. Lei n. 8.666, de 21 de junho de 1993. Regulamenta o art. 37, inciso XXI, da Constituição Federal, institui normas para licitações e contratos da Administração Pública e dá outras providências. Diário Oficial da União, p. 8269, 22 jun. 1993. Disponível em: http:// legislacao.planalto.gov.br/legisla/legislacao.nsf/Viw_Identificacao/lei\%20 8.666-1993?OpenDocument. Acesso em: 3 nov. 2017.

COMPANHIA NACIONAL DE ABASTECIMENTO. Programa de Aquisição de Alimentos - PAA: Legislação básica. Brasília: 2013.

CONTI, Irio Luiz. Organizações sociais e políticas públicas: inserção da Fetraf-Sul nas políticas públicas de segurança alimentar e nutricional. 2016. 329 f., il. Tese (Doutorado em Desenvolvimento Rural) - Faculdade de Ciências Econômicas, Universidade Federal do Rio Grande do Sul, Porto Alegre, 2016.

D’ARAÚJO, Maria Celina (org.). Governo Lula: contornos sociais e políticos da elite no poder. Rio de Janeiro: Centro de Pesquisa e Documentação de História Contemporânea do Brasil, 2007.

DELGADO, Guilherme. Pesquisa de avaliação da concepção e implementação do Programa de Aquisição de Alimentos (PAA): relatório de avaliação do PAA. Projeto BRA 03/034. Brasília: Companhia Nacional de Abastecimento/ Programa das Nações Unidas para o Desenvolvimento, 2013. 
DELGADO, Guilherme. O papel do rural no desenvolvimento nacional: da modernização conservadora dos anos 1970 ao Governo Lula. In: DELGADO, Guilherme. Brasil rural em debate: coletânea de artigos. Brasília: Conselho Nacional de Desenvolvimento Rural Sustentável/ Núcleo de Educação à Distância, 2010. p. 28-78.

EMIRBAYER, Mustafa; MISCHE, Ann. What is Agency? The American journal of sociology, Chicago, v. 103, n. 4, p. 962-1023, jan. 1998.

GOFFMAN, Erving. Frame analysis. New York: Harper, 1974.

GOFFMAN, Erving. Os quadros da experiência social: uma perspectiva de análise. Petrópolis: Editora Vozes, 2012.

GRISA, Catia. Políticas públicas para a agricultura familiar no Brasil: produção e institucionalização das ideias, 2012. 280 f. Tese (Doutorado em Ciências Sociais) - Programa de Pós-Graduação em Desenvolvimento, Agricultura e Sociedade, Universidade Federal Rural do Rio de Janeiro, Rio de Janeiro, 2012.

GRISA, Catia; KATO, Karina Y. Martins; FLEXOR, Georges Gerard. Capacidades estatais para o desenvolvimento rural no Brasil: análise das políticas públicas para a agricultura familiar. Sociedade e cultura, Goiânia, v. 20, n. 1, p. 13-38, 2017.

GRISA, Catia; SCHNEIDER, Sergio. Três gerações de políticas públicas para a agricultura familiar e formas de interação entre sociedade e Estado no Brasil. Revista de Economia e Sociologia Rural, Brasília, v. 52, supl. 1, p. 125-146, 2015.

GRISA, Catia; TRINCHES, Rozane Maria. Entre mudanças e conservadorismos: uma análise dos programas de aquisição de alimentos (PAA e PNAE) a partir da retórica da intransigência. Revista Nera, Presidente Prudente, ano 18, n. 26, edição especial, p. 10-27, 2015.

HAY, Colin. Constructivist Institutionalism. In: BINDER, Sarah A.; RHODES, Roderick. A. W; ROCKMAN, Bert A. The Oxford Handbook of Political Institutions. Oxford: Oxford University Press, 2008. 
INSTITUTO CIDADANIA. Projeto Fome Zero: uma proposta de política de segurança alimentar para o Brasil. São Paulo: Instituto Cidadania, 2001. LICHTERMAN, P. Beyond the Seesaw Model: public commitment in a culture of self-fulfillment. Sociological Theory, v. 13, n. 3, p. 275-300, 1995. MENDONÇA, Ricardo Fabrino; SIMÕES, Paula Guimarães. Enquadramento: diferentes operacionalizações analíticas de um conceito. Revista Brasileira de Ciências Sociais, v. 27, n. 79, p. 187-235, jun. 2012.

MINAYO, C. S. Raízes da fome. Petrópolis, RJ: Editora Vozes, 1985.

MÜLLER, Ana Luiza. A construção das políticas públicas para a agricultura familiar no Brasil: o caso do Programa de Aquisição de Alimentos. 2007. 128 f., il. Dissertação (Mestrado em Desenvolvimento Rural) - Programa de Pós-Graduação em Desenvolvimento Rural, Universidade Federal do Rio Grande do Sul, Porto Alegre, 2007.

NUNES, Jordão Horta. Interacionismo simbólico e movimentos sociais: enquadrando a intervenção. Revista Sociedade e Estado, Brasília, v. 28, n. 2, p. 257-277, mai./ago. 2013.

OLIVEIRA, Jonatan Alexandre. Políticas públicas para agricultura familiar: o caso do Programa de Aquisição de Alimentos (PAA) no estado de São Paulo, Brasil. 2015. 103 f., il.Dissertação (Mestrado em Geografia) - Instituto de Geociências Exatas, Universidade Estadual de São Paulo, São Paulo, 2015.

PELIANO, Ana Maria T. M. (Coord.). O mapa da fome: subsídios à formulação de uma política de segurança alimentar. Brasília: Ipea, 1993. (Documento de política, n. 14).

PICOLOTTO, Everton L. Os atores da construção da categoria Agricultura Familiar no Brasil. Revista de Economia e Sociologia Rural, Piracicaba, v. 52, supl. 1, p. 63-84, 2014. 
PIRES, Roberto; GOMIDE, Alexandre. Capacidades estatais e democracia: a abordagem dos arranjos institucionais para análise de políticas públicas. In: PIRES, Roberto; GOMIDE, Alexandre. Capacidades estatais e democracia: arranjos institucionais de políticas públicas. Texto para Discussão. Brasília: Ipea, 2014. p. 15-28.

PORTO, Sílvio Isoppo. Programa de Aquisição de Alimentos (PAA): política pública de fortalecimento da agricultura familiar e da agroecologia no Brasil. 2014. 132 f., il. Dissertação (Mestrado em Agroecologia) - Programa Oficial de Postgrado em Agroecología, Universidad Internacional de Andalucía, Espanha, 2014.

RECH, Carla Michele; SILVA, Marcelo Kunrath. Ativismo institucional como categoria analítica para o estudo das práticas políticas dos movimentos sociais no Brasil. SEMINÁRIO NACIONAL DE SOCIOLOGIA DA UFS, 1., 2016, Aracaju. Anais [...] Aracaju: Universidade Federal do Sergipe, 2016. SANTORO, Wayne A.; McGUIRE, Gail M. Social movement insiders: the impact of institutional activists on affirmative action and comparable worth policies. Social Problems, v. 44, n. 4, p. 503-519, nov. 1997.

SCHMIDT, Vivien A. Discursive institutionalism: the explanatory power of ideas and discourse. Political Science, Palo Alto, v. 11, p. 303-326, jun. 2008. SUREL, Yves. The role of cognitive and normative frames in policy-making. Journal of European Public Policy, v. 7, n. 4, p. 495-512, 2000. 